Studia Anglica Posnaniensia 45/1, 2009

(C) School of English, Adam Mickiewicz University, Poznań, Poland

doi: 10.2478/v10121-009-0006-5

\title{
ON ADJECTIVAL CONNOTATIONS
}

\author{
GÖRAN KJELLMER
}

Gothenburg University

\begin{abstract}
Connotations are elusive semantic elements. Although they are often specific to individual speakers, many of them are sufficiently general to serve as general communicative elements. The paper suggests a device by means of which adjectival connotations, whether of the individual or the general type, can be pinpointed. The device is simply the sequence "ADJ" but not $\mathrm{ADJ}^{2}$ ", where $\mathrm{ADJ}^{2}$ is seen to enrich the connotational semantics of $\mathrm{ADJ}^{1}$. Thus for example the use of a phrase like desirable but not essential may indicate that desirable normally contains an element of essential, though perhaps not in the situation where it is used. It is pointed out that $\mathrm{ADJ}^{2}$ often represents an intensification of the semantic content of $\mathrm{ADJ}^{1}$.
\end{abstract}

\section{Introduction}

In unreflected, untechnical language, words are often thought of as semantically monolithic. Strong "means" 'powerful', slow "means" "not fast', loud "means" 'noisy', and similarly for the other word classes. Those are denotational meanings, describing the objective content of the word and in many ways the most important part of a word's semantic constitution. But in order to gain a more precise idea of what the writer or speaker wishes to convey it is necessary that the reader or hearer have some conception of the connotations surrounding the words used. Briefly put, connotations are the often emotional and/or personal associations that are linked with certain words in the linguistic world of the language user. It is the aim of this paper to show how connotations can be made visible within one linguistic domain, the adjectives. 


\title{
2. Definitions
}

The distinction between denotation and connotation, as the concepts are used now, goes ultimately back to John Stuart Mill, who distinguished "between the connotation, or understood meaning, of terms and the denotation, or real meaning". ${ }^{1}$ According to Lyons (1977: 176),

\begin{abstract}
The reason why Mill chose the term 'connote' is clear enough. As he says himself, it is intended to suggest that what he calls the signification of the attributes of a subject is something additional to the signification, or denotation, of all the subjects which possess these attributes. Somewhat similar is the notion which underlies the non-philosophical use of the term 'connotation' according to which we might say, for example, that a particular word has a pleasant or desirable connotation. In this usage, the connotation of a word is thought of as a [sic] emotive or affective component additional to its central meaning.
\end{abstract}

Although the definitions of other scholars vary a little, their essence is more or less the same:

"The connotations of a word are those associations connected with a word-form that are emotional in character and which are not necessarily part of the definition of the word in question" (Warren 1988: 80),

"CONNOTATION $[\mathrm{S} . .$.$] are relevant [. .$.$] to social and stylistic aspects of meaning"$ (Allan 1992: 395),

"LEXICAL CONNOTATIONS are semantic components that, without being part of the definition of [the headword] L, are ascribed to L by the language in question. Thus air connotes 'emptiness', because of the expression 'hot air', as in All this is hot air!' (Mel’čuk 1992: 334),

"CONNOTATION. The personal and emotional associations which are suggested by words, and which thus form part of their meaning, for individual speakers" (Crystal 1992),

"CONNOTATION. The emotive or affective component of a linguistic expression (such as style, idiolect, dialect, and emotional charge), which is superimposed upon its basic meaning and which - in contrast to the static conceptual meaning - is difficult to describe generally and context-independently" (Bussmann 1996).

$1 \quad U^{*} X^{*}$ L encyclopedia of world biography 2003 


\section{Aims}

It is true that connotations are often personal and not shared with other speakers, but, "because people do have some common experiences, many lexemes in the language have connotations which would be shared by large groups of speakers" (Crystal 1995: 171). It is such connotations that are important, and sometimes even necessary, for the hearer to register if he or she is to take in the full import of what is being said. However, their identification can be problematic because of their subtle and elusive character. How could they be distinguished in a reasonably systematic fashion? In this paper I am going to suggest the use of a device that will elicit a number of such connotations. In doing so I will make use of language material from the 56-million-word CobuildDirect Corpus and the 100-million-word British National Corpus (BNC).

The device in question will be referred to as "ADJ" but not $\mathrm{ADJ}^{2}$ ". I hope to demonstrate its usefulness by means of a few simple examples, such as the following: ${ }^{2}$

1) Every effort is made to make you feel at home, with the service attentive but not intrusive: perfect for unwinding after a day of excitement.

(Corpus: ukmags/03. Text: N0000000764).

The writer is saying that the service is attentive, but not so much so that it becomes intrusive. Why does she say that? Clearly because there is a risk that prospective customers might suspect that attentive service would involve a certain measure of (unwanted) intrusiveness. In other words, the writer is suggesting, obliquely, that there is slight tinge, or connotation, of intrusiveness surrounding attentive.

2) Hart is ambitious but not ruthless in achieving personal aims.

(BNC: ECT 1291).

Ambition can be seen as bordering on ruthlessness, and the writer is concerned to show that the ruthless connotation of ambitious is not relevant here. At the same time he demonstrates by doing so the presence of that very connotation.

3) A shirt that's warm but not bulky for your next trip to Alaska

(Corpus: usephem Text: E9000000114).

2 Examples in this paper come from the 56-million-word CobuildDirect Corpus and from the 100-million-word BNC. 
Here $\mathrm{ADJ}^{3}$ suggests that warm in connection with clothing calls forth the idea, connotation, of bulkiness.

\section{Types of connotation}

Backhouse (1992) distinguishes three types of connotation: those used with reference to expressive components of meaning, those reflecting social or situational circumstances of use, and those deriving from general cultural associations of what is denoted by the lexical unit. It is clear from the corpus material that the formula "ADJ" but not $\mathrm{ADJ}^{2}$ " will primarily elicit connotations of the first type, but then not only those expressing value-judgements. (The third type, in particular, strikes one as being rare). The connotations tend to fall into two broad types, "factual" and "judgemental". Factual are those where reference is, or can be, made to objective evidence, and judgemental are those representing the speaker/writer's opinion. Here are some examples from the corpora:

\section{Factual}

4) Dandruff. It is controllable but not curable

5) it [the tradition] has become attenuated but not extinct

6) A more autonomous but not fully independent Algeria

7) stability that is distinct but not separable from the biological organization that maintains it tax which was due but not paid on or before the due date

\section{Judgemental}

8) Their relaxation is active but not energetic

9) The two ships offer adequate but not exciting service

10) Scholarly and aloof but not infantile

11) Hart is ambitious but not ruthless

12) Elsie was amiable but not very bright

13) The Manor is attractive but not remarkable as a building

14) Disappointed but not surprised

There are many more of the judgemental than of the factual type.

\section{Intensification}

It is characteristic of the formula "ADJ ${ }^{1}$ but not $\mathrm{ADJ}^{2}$ " that $\mathrm{ADJ}^{2}$ represents an intensification of the meaning of $\mathrm{ADJ}^{1}$. Intensification is here taken to mean the

3 "The plant should be in good, but not scorching hot, light". 
presence in $\mathrm{ADJ}^{2}$ of more of the quality or quantity already present in $\mathrm{ADJ}^{1}$. This of course presupposes that the two adjectives belong to the same semantic sphere. We may say difficult but not impossible, slim but not skinny, exceptional but not unique, but hardly *difficult but not skinny, *slim but not illogical or *exceptional but not intrusive. Nor would we say *impossible but not difficult, etc., where the intensification would go the wrong way. Most adjectives have several dimensions along which they can be intensified depending on the contexts in which they are being used, and the intensificational possibilities inherent in each adjective are very much part of its semantic setup. As a general description of the semantics of the structure being discussed one may say that the first adjective, $\mathrm{ADJ}^{1}$, is close in meaning to the second adjective, $\mathrm{ADJ}^{2}$, without in general (quite) attaining the level of intensification represented by it. The connotations of $\mathrm{ADJ}^{1}$ are provided by $\mathrm{ADJ}^{2}$. To take a few examples again:

15) Other people used mental images involving objects similar but not identical to the rbcs

(Corpus: usbooks/09. Text: B9000001453./09. Text: B9000000447).

16) Accommodation is good, but not luxurious.

(Corpus: sunnow/17. Text: N9119980510).

Even a high degree of similarity does not amount to total identity; even very good accommodation need not be luxurious, etc. Although the formula makes it explicit that $\mathrm{ADJ}^{1}$ is not the same as $\mathrm{ADJ}^{2}$, the fact that it needs to be stated shows that the two adjectives are in fact semantically quite close, and that there is a suggestion of $\mathrm{ADJ}^{2}$ in $\mathrm{ADJ}^{1}$.

There is one situation, however, where the " $\mathrm{ADJ}^{1}$ but not $\mathrm{ADJ}^{2}$ " formula does not suggest intensification, namely when two concepts are presented on an equal footing and the writer is referring to only one of them. As those cases do not provide the kind of connotational information that is being focused here, they are left out of account. Some examples are:

17) regional policies have moderated the relative but not the absolute differences in the unemployment rates

(BNC: FR4 1054).

18) the amplitude of the wave form over the right but not the left hemisphere

$(B N C$ : FED 584).

19) President Habyarimana yesterday announced a partial ammnesty [sic] for criminal, but not political prisoners

(Corpus: bbc/06. Text: S1000900909). 
Intensification can be brought about by $\mathrm{ADJ}^{1}$ being duplicated and provided with a modifier. Some such examples are:

20) To sum it all up, it's good but not that good.

(BNC: C87 662).

21) all I want is a cup of tea, weak but not too weak.

(BNC: A7C 1457).

22) This probably means that the remedy was close but not quite close enough to give any sustained relief.

(BNC: B1R 563).

23) I thought the sex stuff was a bit weird but not so weird that I didn't want to get involved.

(BNC: A6E 895).

Here the expected duplicated adjective is sometimes left out:

24) It's all hysterically, and unintentionally, funny, but not [funny] enough to warrant an hour and 40 minutes of your time.

(Corpus: today/11. Text: N6000950602).

25) A bit depressing but not entirely [depressing].

(BNC: B0H 1276).

However, the normal pattern with cases of modified $\mathrm{ADJ}^{2}$ is, as before, that $\mathrm{ADJ}^{2}$ is different from $\mathrm{ADJ}^{1}$, of which it represents an intensified variant:

26) "It's very fruity but not too sweet", said one.

(Corpus: today/11. Text: N6000950909).

27) Simmer until the mixture is the right consistency - still liquid but not too runny.

(Corpus: ukephem/02. Text: E0000002072).

28) He was courageous, but not too cunning.

(Corpus: times/10. Text: N2000951118).

So fruity has connotations of sweetness, liquid of runniness, and courageous, apparently, of cunning.

The linguistic convention that $\mathrm{ADJ}^{2}$ is an intensified version of $\mathrm{ADJ}^{1}$ in the formula " $\mathrm{ADJ}^{1}$ but not $\mathrm{ADJ}^{2}$ " has interesting consequences. If the convention had not existed the following example would have been incomprehensible. 
29) He was Lloyd, yet he wasn't the Lloyd she knew. He was more intense, voraciously attacking her body with his. Rough, but not rough. Gentle but not gentle. She pulled his face down until her lips were against his.

(Corpus: ukbooks/08. Text: B0000000115).

On the face of it, "rough but not rough" is gibberish. But the convention tells us that the second rough is now an intensified version of the first rough, perhaps meaning 'very rough' or 'too rough', and the second gentle an intensified version of the first gentle, perhaps 'very gentle' or 'too gentle'. So Lloyd was rough, but not too rough, and also gentle, but not too gentle. Note the description of him: "He was more intense", which is precisely what the formulas (rough but not rough, gentle but not gentle) convey.

It will have been seen that connotations, as understood in this paper, are not the same as synonyms. This point will be discussed towards the end of the paper.

\section{Connotations as constitutive semantic elements}

The structure "ADJ" but not $\mathrm{ADJ}^{2}$ " is fairly common (there are more than 400 such cases in the CobuildDirect Corpus and more than 600 in the BNC); it may thus provide a picture of the dimensions in which different adjectives can be intensified and hence contribute to their semantic description. In many or most cases, the more intense word, $\mathrm{ADJ}^{2}$, is more or less what the reader would expect: cool but not cold, damp but not wet, good but not perfect, but many others are surprising and therefore extra informative about the connotations of the adjectives. We shall see some examples of this below.

As the second adjective in our formula $\left(\mathrm{ADJ}^{2}\right)$ hints at what can be suspected of being a part of the semantic constitution of the first $\left(\mathrm{ADJ}^{1}\right), \mathrm{ADJ}^{2}$ can often provide an interesting angle on the meaning of $\mathrm{ADJ}^{1}$. For example:

30) The verdict is harsh but not illogical.

(Corpus: times/10. Text: N2000960217).

31) he has led a tough life and leaves us uneasy but not despondent.

(Corpus: oznews/01. Text: N5000951028).

32) He was foreign but not French. Dutch or German perhaps.

(BNC: HP0 2910).

In (30), harshness is seen as bordering on the illogical, and in (20) uneasiness is close to despondency. (32) reveals that foreign is more naturally associated with French than with other nationalities. The use of the structure thus uncovers sometimes unexpected strands in the semantic complex of the words. 
One of the striking things about the "ADJ but not $\mathrm{ADJ}^{2}$ " formula is that fine semantic distinctions can be made, perhaps such distinctions as would not ordinarily have been noticed. In this way subtle nuances can be made visible. Examples (33)-(37) will demonstrate this.

33) Abrasive, but not arrogant, there is no edge to him

(Corpus: ukmags/03. Text: N0000000054).

34) I think the situation of our people is desperate but not hopeless says Lucky (Corpus: ukmags/03. Text: N0000000869).

35) the AC Ace, a gawky but not inelegant spaceframe design by race car specialist John Tojeiro.

(Corpus: ukmags/03. Text: N0000000728).

36) I come across the house I have been seeking. It is secluded but not shut off. (BNC: H9G 2827).

37) These accounts are contradictory but not incompatible:

(BNC: EFX 689).

In (33) "abrasive" seems to mean "unkind, unpleasant and rude in the way [someone talks] to other people' (Sinclair 1995) but without the rudeness that comes with a feeling of superiority, arrogance, which would otherwise be associated with abrasiveness. To the writer of (34), despair, although suggestive of hopelessness, is not quite as bad as hopelessness itself, and to the writer of (35) gawky means 'awkward' and 'clumsy' and suggests lack of elegance though not in the present case. (36) shows that the writer regards seclusion as being related to but not quite as definite a form of isolation as being shut off. (37), finally, presents the thought-provoking case where contradiction though close enough in meaning to incompatibility is contrasted with it. Many nice distinctions are made:

38) complex variants which are law-related but not necessarily legal

(BNC: CHC 716).

39) I had a neutral but not disinterested role.

(BNC: CRS 1285).

40) problems when new but not original ideas are introduced.

(BNC: A26 287). 
41) "The aim is to keep them segregated, but not apart", one mod source said.

(Corpus: times/10. Text: N2000960415).

42) Creative, but not necessarily productive.

(Corpus: ukbooks/08. Text: B0000000622).

43) Both President Bush and Iraq's leader Saddam Hussein knelt in prayer today, both in capitals quiet but not calm.

(Corpus: npr/07. Text: S2000910117).

44) Last but not ultimate; Concert

(Corpus: times/10. Text: N2000951204).

The meaning of $\mathrm{ADJ}^{1}$ can thus be seen as enriched by $\mathrm{ADJ}^{2}$.

Sometimes the two adjectives are so close in meaning that it is difficult to see how the first adjective differs from the second in intensity, but nevertheless the formula indicates that the speaker or writer sees more of the quality common to both adjectives in $\mathrm{ADJ}^{2}$ than in $\mathrm{ADJ}^{1}$ :

45) material which is indecent but not obscene

(BNC: BNE 611).

46) They were all men. Nude but not naked.

(BNC: A0R 129).

Not surprisingly, then, indecency has connotations of obscenity, and nudity immediately suggests nakedness.

The connotations often give an interesting picture of the preconceptions, expectations and perhaps previous experience of the writers. Here are some examples:

47) She's young but not daft

(Corpus: today/11. Text: N6000940101).

48) The Tories say they're philosophical but not angry.

(BNC: KRM 441).

49) he was proud but not stupid

(BNC: A6J 832).

50) Mrs Bean was fat but not fierce, very placid in fact, and cheerful.

(BNC: AT4 638). 
51) It was a noisy but not a violent affair

(BNC: EDA 170).

52) The audiences were noisy but not, so far, violent

(BNC: GVT 2619).

53) Noisy but not brattish

(Corpus: ukmags/03. Text: N0000000351).

54) Angry, loud but not unrefined, Ridgeway Bennett continue to make a solid contribution to cultural commentary on sexuality, sex and empowerment.

(Corpus: ukmags/03. Text: N0000000369).

55) LESBIAN 20, cultured but not weird, likes clubbing and has varied interests

(Corpus: ukmags/03. Text: N0000000934).

56) We can speak our minds then and there - being honest but not destructive.

$(B N C: \mathrm{B} 21260)$

\section{Contextual influence}

The situational context in which the adjectives occur has a determining effect on their connotations. Soft occurs with the following connotations in the BNC: coloured, mushy, disintegrated, brown, browned, sticky, and with brown, sticky, sickly, greasy in Cobuild. The context, as could be guessed, is nearly always cooking recipes. And that large among its connotations has bright is explained by its reference to the celestial constellation Pegasus.

It was indicated above that the complexity of connotations surrounding individual adjectives could be demonstrated by means of the formula under discussion. It is obvious, however, that the demonstrable complexity of an adjective is dependent on its frequency and use in the formula: an adjective used only once in this way will show only one such connotation (if that). Adjectives with more general meaning (e.g. good) and capable of being used in a multitude of different contexts will be more frequent and have more connotations than those with more specific meaning (e.g. futuristic). In the corpora, a number of common adjectives are frequent enough in the structure to present a variety of connotations. Let us select from the whole repertoire of adjectives the reasonably frequent good, interesting, possible, strong, unusual and useful to see what their connotations are, as elicited by the "ADJ but not $\mathrm{ADJ}^{2}$ " formula.

Good is obviously as positive word, and in the BNC it is associated with wonderful, sharp, dazzling and outstanding. In Cobuild its associations go to memo- 
rable, perfect, fantastic, great, suitable, scorching hot, luxurious, certain. ${ }^{4}$ The connotations are not unexpected and extend the semantic possibilities of good in different though related directions, adding to the basic meaning of simple good.

Interesting has a different flora of connotations: consistent, untypical, demanding, romantic, surprising, easy, ideal in the BNC, and desperate and outrageous in Cobuild. Here some of the connotations are unexpected and contribute to a multifaceted picture of the adjective.

Possible is even more diverse in its connotations: commercial, usual, happening, necessary, inevitable, certain in the BNC, and cost-effective, probable, romantic and certain in Cobuild. The contexts in which the formula is used clearly condition the choice of its connotations.

Some, but perhaps not all, of the connotations of strong may be more in line with one's expectations: thick, invincible, direct, dominant, overpowering in the $B N C$, and dominant, universal, wild in Cobuild.

Unusual is coupled with impractical, unique and unknown in the $B N C$, and with unheard of and bizarre in Cobuild.

Useful, finally, is associated with reliable, personal, essential and consolidated in the BNC, and with essential, conclusive and necessary in Cobuild.

In some cases (good and perhaps strong), the connotations are more or less to be expected. In other cases they are certainly unexpected and contribute to colouring the semantic Gestalt of the adjectives. Anyone who becomes familiar with them will then be prepared for them and see them as potential aids in his/her interpretation of the adjectives.

\section{Sense-related words}

Lists of connotations elicited by means of the "ADJ ${ }^{1}$ but not $\mathrm{ADJ}^{2}$ " formula, such as those just given for good, etc., are superficially not unlike those found for the same words in books of synonyms or in thesauri. However, closer scrutiny reveals that we are dealing with two different categories of concepts. Roget's Thesaurus (Kirkpatrick 1987) does not want to call itself a synonym dictionary (p. vii), but what it lists under each entry could fairly be described as sense-related words, thus a wider term than synonyms. If now we compare the connotations of good, possible, strong, unusual and useful with the senserelated words given for them in Roget (interesting is not given as a separate entry), we shall see that the two sets are different; there is not even a single case of overlap. To illustrate, let us compare the elicited connotations of good with Roget's sense-related words under good.

4 "The plant should be in good, but not scorching hot, light". 


$\begin{array}{ll}\text { Connotations: } & \text { Roget's sense-related words: } \\ \text { wonderful } & \text { savoury } \\ \text { sharp } & \text { elegant } \\ \text { dazzling } & \text { good } \\ \text { outstanding } & \text { utility } \\ \text { memorable } & \text { useful } \\ \text { perfect } & \text { excellent } \\ \text { fantastic } & \text { skilful } \\ \text { great } & \text { prosperity } \\ \text { suitable } & \text { obedient } \\ \text { scorching hot } & \text { pleasurable } \\ \text { luxurious } & \text { amiable } \\ \text { certain } & \text { benevolent } \\ & \text { right } \\ & \text { honourable } \\ & \text { virtuous } \\ & \text { pure } \\ & \text { pious }\end{array}$

Perhaps we could say that the emotional temperature is higher in the connotations than in the sense-related words. Nor would we expect connotations derived by means of the "ADJ ${ }^{1}$ but not $\mathrm{ADJ}^{2 \text { " }}$ formula to be synonymous with the core adjective - the formula states that they are NOT the same. Nevertheless, even if connotations are not the same as synonyms, generally speaking, there is a shady area between the two, so that sense-related words occasionally turn up as connotations. For instance, the (fabricated) example,

57) His car was good but not elegant,

seems quite acceptable, where $\operatorname{ADJ}^{1}$ (good) has the connotation 'elegant' $\left(\mathrm{ADJ}^{2}\right)$, one of Roget's sense-related words. This come as no surprise; it was pointed out above that the two adjectives concerned, $\mathrm{ADJ}^{1}$ and $\mathrm{ADJ}^{2}$, move in the same semantic sphere.

\section{Collocations}

Some of the connotations occur repeatedly or frequently, so that they become a kind of fixed expressions or collocations together with their source adjectives. Such collocations are e.g.:

58) desirable but not essential

59) difficult but not desperate 
60) difficult but not impossible

61) last but not least ${ }^{5}$

62) necessary but not sufficient

63) similar but not identical.

\section{Conclusions}

Connotations are the elusive associations clustering round certain words. Their very elusiveness makes them difficult to elicit and pin down. This paper suggests that connotations of adjectives can be elicited by means of the frequent phrase "ADJ ${ }^{1}$ but not $\mathrm{ADJ}^{2}$ ", as in "good but not perfect", where the second adjective indicates a possible connotation of the first. The connotations elicited in this way vary with the contexts in which the key word $\left(\mathrm{ADJ}^{1}\right)$ is used and contribute to giving it a more complete semantic shape.

\section{REFERENCES}

Allan, Keith

1992 "Semantics: An overview", in: Bright William (ed.), 394-398.

Backhouse, Anthony E.

1992 "Connotation", in: Bright William (ed.), 297-298.

$B N C=$ British National Corpus, see Leech and Smith 2000.

Bright, William (ed.)

1992 International Encyclopedia of Linguistics. New York - Oxford: Oxford University Press.

Bussmann, Hadumod (ed.)

1996 Routledge dictionary of language and linguistics. London - New York: Routledge. Crystal, David

1992 An encyclopedic dictionary of language and languages. Oxford: Blackwell.

1995 The Cambridge encyclopedia of the English language. Cambridge: Cambridge University Press.

Johannesson, Nils-Lennart (ed.)

1988 The dress of thought. Lund: Studentlitteratur.

Kirkpatrick, Betty (ed.)

1987 Roget's thesaurus of English words and phrases. London: Longman.

Leech, Geoffrey, and Nick Smith

2000 Manual to accompany The British National Corpus (Version 2) with improved wordclass tagging. Oxford: Oxford University Computing Services.

Lyons, John

2000 Semantics. 2 vols. Cambridge: Cambridge University Press.

5 “And least but not last, the media" (Corpus N5000951103) is presumably a slip of the pen. 
Mel'čuk, Igor

1992 "Lexicon", in: Bright William (ed.), 332-335.

Sinclair, John (ed. in chief)

1995 Collins COBUILD dictionary. London: HarperCollins.

Warren, Beatrice

1988 “Semantics: Word meaning”, in: Johannesson Nils-Lennart, 61-95.

\section{INTERNET SOURCES}

CobuildDirect Corpus, an on-line service: telnet://titan.collins.co.uk

$U^{*} X^{*} L$ Encyclopedia of world biography 2003. available at:

http://www.encyclopedia.com/doc/1G2-3437500539.html (date of access: May 2009). 